Available online at www.eccomasproceedia.org

Eccomas Proceedia COMPDYN (2021) 1476-1491

ECCOMAS

Proceedia
COMPDYN 2021

$8^{\text {th }}$ ECCOMAS Thematic Conference on Computational Methods in Structural Dynamics and Earthquake Engineering M. Papadrakakis, M. Fragiadakis (eds.)

\title{
A TECHNIQUE FOR TIME INTEGRATION WITH STEPS LARGER THAN THE EXCITATION STEPS: REVIEW OF THE PAST ADDRESSING THE EXISTING CHALLENGES AND A PERSPECTIVE OF THE FUTURE
}

\author{
Aram Soroushian \\ ${ }^{1}$ International Institute of Earthquake Engineering and Seismology (IIEES) \\ No. 21, West Arghavan St., North Dibajee St., S. Lavasani St., Tehran 19537, Iran \\ e-mail: a.soroushian@iiees.ac.ir
}

\begin{abstract}
Time history analysis using a time integration method is a powerful broadly accepted tool for structural dynamic analysis. In practical areas, such as earthquake engineering, computations based on time history analysis might be computationally very expensive. In 2008, a technique was proposed to considerably reduce the computational effort by reducing the data in the earthquake record. This technique, which is recently named as a SEB THAAT, is reviewed in this paper. After a brief review on the formulation and implementation, the positive points, the limitations, and the challenges facing versatile implementation of the SEB THAAT are addressed, and a future perspective is presented.
\end{abstract}

Keywords: Time History Analysis, Earthquake Engineering, Computational Effort, SEB THAAT, Existing Challenges, Future Perspective. 


\section{INTRODUCTION}

The true behavior of structural systems is nonlinear and dynamic. Time history analysis using a time integration method is a versatile tool to study structures' nonlinear dynamic behavior. The analysis process is briefly reviewed in Fig. 1. Evidently, the analysis leads to approximate responses and is computationally expensive. Specifically, the run-time may be considerable in many real analyses. The significance of these features highlights in earthquake engineering, where seismic codes require structures' time history analysis considering several ground acceleration records. Also there exist advanced seismic computations such as IDA

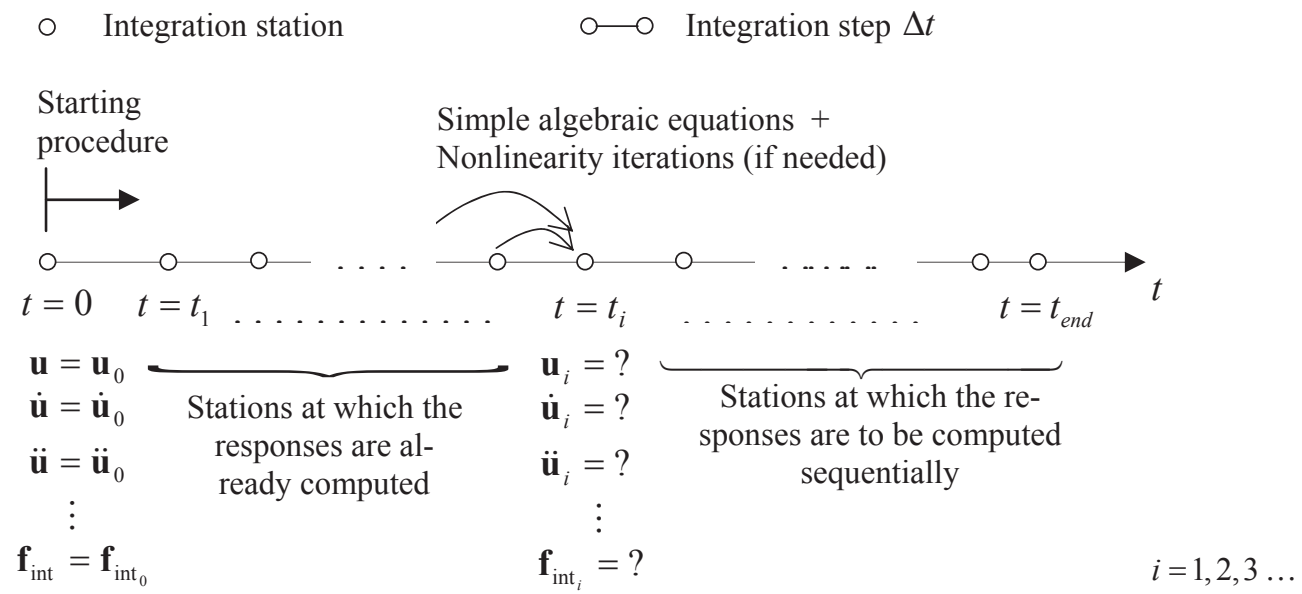

Figure 1: Brief description of the process of time history analysis using a time integration method [1].

(Incremental Dynamic Analysis) [2], for which many time history analyses are essential and the computational effort can be very high. Some main approaches to lessen the computational effort are: (1) reducing the structural systems by replacing the structures finite element models with models with less degrees of freedom [3, 4], (2) reducing the number of essential earthquake records, e.g. see [5-7], (3) reducing the number of oscillatory modes [8,9], and (4) using higher order time integration methods [10-12]. Meanwhile, in the last two decades, approaches are developed to reduce the computational effort by reducing the earthquake records' data [13-15].

The semi-discretized equation of motion can be expressed as [1, 11, 16-19]:

$$
\begin{array}{cl}
\mathbf{M} \ddot{\mathbf{u}}(t)+\mathbf{f}_{\text {int }}(t)=\mathbf{f}(t) & \quad 0 \leq t \leq t_{\text {end }} \\
\text { Initial Conditions : } & \begin{array}{l}
\mathbf{u}(t=0)=\mathbf{u}_{0} \\
\dot{\mathbf{u}}(t=0)=\dot{\mathbf{u}}_{0} \\
\mathbf{f}_{\text {int }}(t=0)=\mathbf{f}_{\text {int }_{0}}
\end{array}
\end{array}
$$

\section{Additional Constraints : $\mathbf{Q}$}

where, $t$ and $t_{\text {end }}$ imply the time and the duration of the dynamic behavior; $\mathbf{M}$ is the mass matrix; $\mathbf{f}_{\text {int }}$ and $\mathbf{f}(t)$ stand for the vectors of internal force and excitation; $\mathbf{u}(t), \dot{\mathbf{u}}(t)$, and $\ddot{\mathbf{u}}(t)$, denote the vectors of displacement, velocity, and acceleration; $\mathbf{u}_{0}, \dot{\mathbf{u}}_{0}$, and $\mathbf{f}_{\text {int }_{0}}$, define the initial status of the model ( $\mathbf{f}_{\text {int }_{0}}$ is essential in presence of material nonlinearity; see [20]); and finally, $\mathbf{Q}$ represents restricting conditions, e.g., additional constraints in problems involved in impact or elastic-plastic behavior [21, 22]. 
For time history analysis of Eq. (1), using a time integration method, the broadly recommended integration-step [1, 23-26] is as follows:

$$
\Delta t=\operatorname{Min}\left(\frac{T}{\chi}, \Delta t_{c r},{ }_{f} \Delta t\right)
$$

where, $T$ is the smallest oscillatory period with worthwhile contribution in the response [26], $\Delta t_{c r}$ stands for the largest integration step leading to numerically stable responses $[10,11,23]$, ${ }_{f} \Delta t$ is the step by which the excitation is digitized [13, 25], and as addressed in [1,23-26],

$$
\chi=\left\{\begin{array}{cl}
10 & \text { when the behavior is linear } \\
100 & \text { when the behavior is nonlinear and there is no impact } \\
1000 & \text { when the behavior is nonlinear and there is impact }
\end{array}\right.
$$

In view of Eqs. (1)-(3), there are techniques [14] that replace the earthquake digitized record and specifically replace $t_{\text {end }}$ with $\left(t_{\text {end }}\right)_{\text {new }}$, such that: (1) after an ordinary time integration analysis, the main features of the response remain almost unchanged, and (2)

$$
\left(t_{\text {end }}\right)_{\text {new }}<t_{\text {end }}
$$

There are also techniques $[13,15]$ that replace the excitation record, such that: (1) the main features of the response, e.g. peak response and frequency content, are almost preserved, and (2) the integration-step $\Delta t$, can be replaced with $(\Delta t)_{n e w}$, satisfying

$$
(\Delta t)_{\text {new }}>\Delta t
$$

The purpose of both of these groups of techniques is to reduce the number of integration steps, and accordingly, lessen the computational run-time and effort; also see [1].

With attention to the following features of a technique in the second group, i.e. the SEB THAAT (Step-Enlargement-Based Time History Analysis Acceleration Technique) [13, 27]:

1. Significant reduction in computational effort; see Table 1,

2. Simple implementation; see $[1,13,28]$

3. Good accuracy for the time history of the response [28]

4. Versatility (see Table 1) [1, 28, 31-34],

5. Having a mathematical basis [13].

the objective of this paper is to review the SEB THAAT, address the existing challenges, and present a perspective of the future.

\section{THE SEB THAAT AND ITS PAST}

The SEB THAAT is developed, based on two mathematical statements, a broadly accepted convention, and a realistic assumption, such that to preserve convergence and its order, for responses obtained from time integration. The two statements are:

1. Consider analysis of Eq. (1) by a time integration method of order $q$. Consider an approximation of the $\mathbf{f}(t)$ in Eq. (1), i.e. $\mathbf{f}_{\text {new }}(t)$, which converges to $\mathbf{f}(t)$ with respect to the integration step, with an order $q^{\prime}$ satisfying $q^{\prime} \geq q$. Analysis of Eq. (1) by that integration method, after replacing $\mathbf{f}(t)$ with $\mathbf{f}_{\text {new }}(t)$, would lead to responses converging with order $q$ (see $[13,35])$. 


\begin{tabular}{|c|c|c|}
\hline System & $\begin{array}{c}\text { Effort reduced in the price } \\
\text { of negligible change in } \\
\text { accuracy }(\%)\end{array}$ & Details \\
\hline Shear frames & $60-80$ & $\begin{array}{l}\text { A few linear shear frames subjected to different } \\
\text { excitations }\end{array}$ \\
\hline Residential buildings & $50-90$ & $\begin{array}{c}\text { More than } 200 \text { buildings structures with linear } \\
\text { and nonlinear behavior and regularity and irregu- } \\
\text { larity in plan or height subjected to different exci- } \\
\text { tations }\end{array}$ \\
\hline A thirty-storey building & 50 & $\begin{array}{l}\text { A thirty-storey steel three-dimensional frame } \\
\text { subjected to two different excitations }\end{array}$ \\
\hline Bridges & $30-80$ & $\begin{array}{c}\text { About } 20 \text { real bridges with linear and nonlinear } \\
\text { behaviors, some with pre-stressed elements, sub- } \\
\text { jected to different excitations }\end{array}$ \\
\hline $\begin{array}{l}\text { Power station, Cooling } \\
\text { tower, Space structure, } \\
\text { Silo }\end{array}$ & $>50$ & $\begin{array}{l}\text { One or two of each special structure, considering } \\
\text { linear and nonlinear behavior and different near- } \\
\text { field and far-field excitations and different inte- } \\
\text { gration schemes }\end{array}$ \\
\hline Earth dams & $<80$ & $\begin{array}{l}\text { Several earth dams each subjected to many } \\
\text { earthquake records }\end{array}$ \\
\hline $\begin{array}{l}\text { Milad } \\
\text { telecommunication tower }\end{array}$ & $50-70$ & $\begin{array}{l}\text { Considering linear and nonlinear behavior, near- } \\
\text { field and far-field excitations, and different inte- } \\
\text { gration schemes }\end{array}$ \\
\hline $\begin{array}{l}\text { Structural systems } \\
\text { damped non-classically }\end{array}$ & $30-90$ & $\begin{array}{l}\text { Considering linear and nonlinear behavior, and } \\
\text { different integration schemes }\end{array}$ \\
\hline
\end{tabular}

Table 1: A summary of the tests carried out on the SEB THAAT [1, 27-30].

2. In view of the Taylor series expansion [36], for an arbitrary continuous function of $x$, i.e. $H(x)$,

$$
H(x+\Delta x)+H(x-\Delta x)=2 H(x)+\mathrm{O}\left(\Delta x^{2}\right)
$$

The convention is the second order of accuracy of majority of time integration methods $[1,10$, 11]. An extension of the SEB THAAT disregarding this convention is addressed in [13], the numerical tests are however few; see [37]. And finally, the realistic assumption is:

The $\mathbf{f}(t)$ in the right hand side of Eq. (1), though is available in digitized format, can be considered originally continuous with respect to time.

Provided these considerations, implementation of the SEB THAAT means ordinary time integration analysis after replacing the $\mathbf{f}(t)$ in Eq. (1), digitized in step ${ }_{f} \Delta t$, with a new excitation $\mathbf{f}_{\text {new }}(t)$, digitized in step $\left({ }_{f} \Delta t\right)_{\text {new }}$,

$$
\begin{gathered}
\left({ }_{f} \Delta t\right)_{\text {new }}=n_{f} \Delta t \\
n=2,3,4, \ldots
\end{gathered}
$$

where, $n$ stands for the enlargement scale of the digitization-step (see also Fig. 2), and 


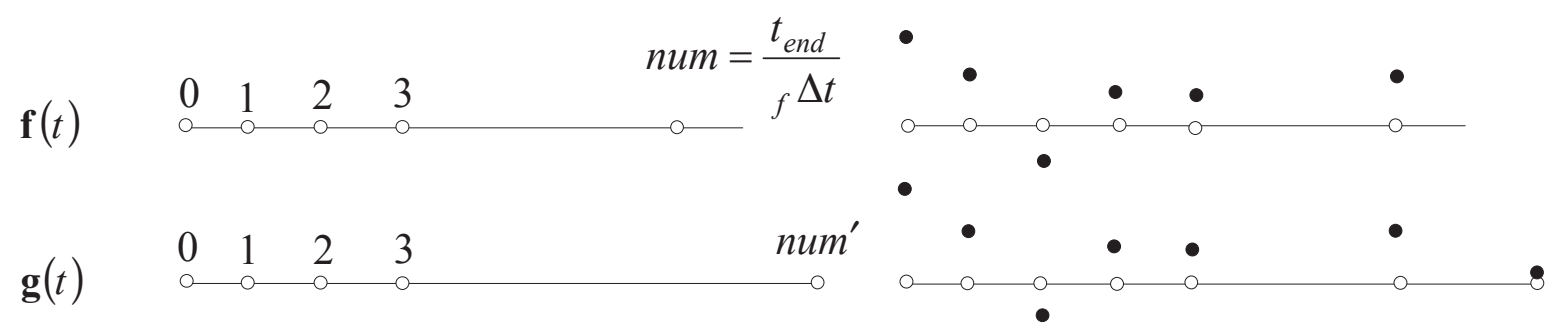

$$
\frac{\text { num }^{\prime}}{n} \in Z^{+}, \text {num } \leq \text { num }^{\prime}<\text { num }+n
$$

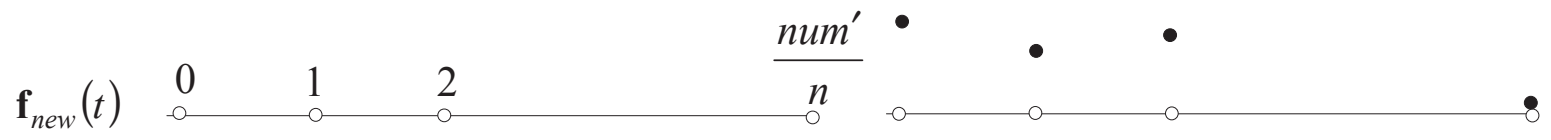

(a)

(b)

Figure 2: Typical changes in the $\mathbf{f}(t)$ in Eq. (1) because of implementation of the SEB THAAT:

(a) Digitization stations, (b) Digitized data.

$$
\begin{aligned}
& \mathbf{f}_{\text {new }}(t)=0, \text { unless when } t=t_{0}, t_{1}, t_{2}, \ldots \text { (the digitization stations) }
\end{aligned}
$$

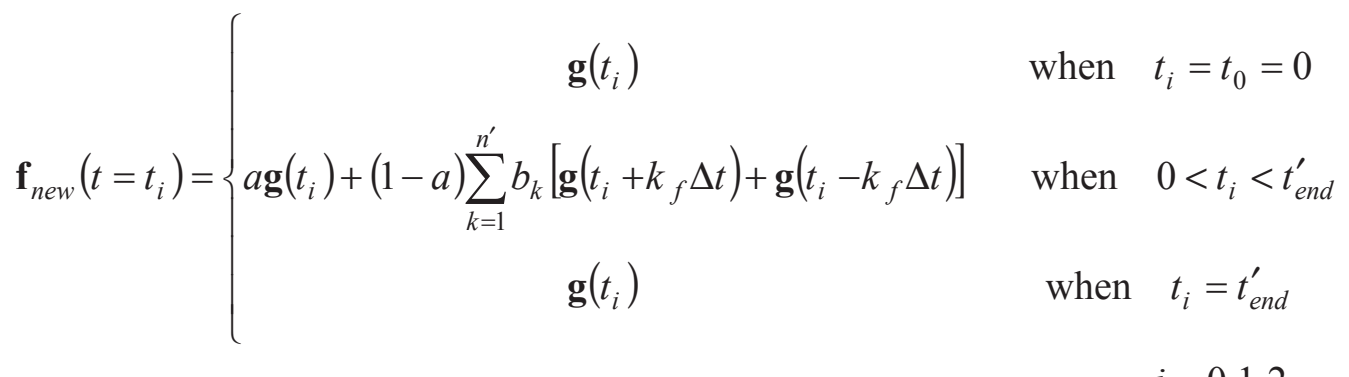

$$
\begin{aligned}
& i=0,1,2, \ldots
\end{aligned}
$$




$$
\begin{aligned}
& n^{\prime}=\left\{\begin{array}{ccc}
n-1 & \text { when } & t_{i}=t_{1}=n_{f} \Delta t \text { or } t_{i}=t_{\text {end }}^{\prime}-n_{f} \Delta t \\
\left\{\begin{array}{cc}
\frac{n}{2} & (\text { even values of } n) \\
\frac{n-1}{2} & \text { (odd values of } n)
\end{array}\right. & \text { when } & n_{f} \Delta t<t_{i}<t_{\text {end }}^{\prime}-n_{f} \Delta t
\end{array}\right. \\
& t_{\text {end }}^{\prime}=\left\{\begin{array}{ccc}
t_{\text {end }} & \text { when } & \frac{t_{\text {end }}}{n_{f} \Delta t} \in Z^{+}\left(Z^{+} \text {implies the set of positive integers }\right) \\
l\left(n_{f} \Delta t\right) & \text { when } & \frac{t_{\text {end }}}{n_{f} \Delta t} \notin Z^{+}, \exists l \in Z^{+}, t_{\text {end }}<l\left(n_{f} \Delta t\right)<t_{\text {end }}+n_{f} \Delta t
\end{array}\right.
\end{aligned}
$$

and extension of Eqs. (8-13) to fractional/real values of $n$ (see Eq. (7.2)), is discussed in [1, 38, 39]. Evidently, in view of Eq. (2), the SEB THAAT is effective and may reduce the run-time, only when

$$
{ }_{f} \Delta t<\operatorname{Min}\left(\frac{T}{\chi}, \Delta t_{c r}\right)
$$

and more, in view of Eqs. (8-13), the effort needed for computing $\mathbf{f}_{\text {new }}(t)$ is negligible compared to that of the time history analysis. Accordingly, the enlargement scale $n$ implies reduction in run-time for linear analyses, where no additional computation is needed to model the nonlinearities. Furthermore, in view of Fig. 1 and notion of computational effort [40, 41], the reductions in run-time and computational effort because of the SEB THAAT are identical, for linear analyses.

There is no guarantee about sufficiency of the accuracy of the results of the SEB THAAT when using arbitrary value of $n$. The reason is that convergence (and its rate) is the only accuracy-related basis of the SEB THAAT. Furthermore, when the SEB THAAT is successful for some value of $n$, upper-bounds will exist on $n$. Considering this and some different theoretical questions, research on the SEB THAAT has been followed in two directions. In one direction, to study the performance of the SEB THAAT, many cases are studied, considering changes of structural system, time integration method, digitized excitation (e.g. far- and near-field earthquakes), etc.. For each case, responses are investigated for the following three questions:

(1) Does ${ }_{f} \Delta t$ governs Eq. (2), for the case under study (see Eq. (14))?

(2) For cases with ${ }_{f} \Delta t$ as the governing term of Eq. (2), can, for some value of $n$, implementation of the SEB THAAT cause no notable loss of accuracy, i.e. is the following statement correct?

$$
\exists n>1: \quad \mathbf{R}_{\text {new }} \cong \mathbf{R}
$$

where, $\mathbf{R}_{\text {new }}$ and $\mathbf{R}$ are the responses obtained from time integration with and without implementation of the SEB THAAT, respectively.

(3) For cases, where ${ }_{f} \Delta t$ governs Eq. (2), is the largest value of $n$ satisfying Eq. (15) ( $\left.n_{\max }\right)$ consistent with Eq. (2), i.e. is the following statement correct?

$$
\forall n \quad \mathbf{R}_{\text {new }} \cong \mathbf{R}: \quad \exists n_{\text {max }} \cong \frac{1}{{ }_{f} \Delta t} \operatorname{Min}\left(\frac{T}{\chi}, \Delta t_{c r}\right): 1<n \leq n_{\text {max }}
$$


The consequence was positive responses in almost all cases [1, 27-30, 37-39, 42-56]. Specifically, a very interesting numerical observation, for two cases reported in $[42,43]$, was the more accuracy after implementation of the SEB THAAT (compared to that of the ordinary analysis). This leads to the fact that the inaccuracy because of the SEB THAAT can be added or subtracted from the inaccuracy originated in the approximate time integration, and accordingly,

$$
\exists \text { Cases : } \quad\left\|\mathbf{R}_{\text {new }}-\mathbf{R}_{\text {exact }}\right\|<\left\|\mathbf{R}-\mathbf{R}_{\text {exact }}\right\|
$$

where, $\mathbf{R}_{\text {exact }}$ stands for the exact response and $\|$.$\| represents arbitrary norm [57]. Finally, it$ is worth noting that the reduction in run-time because of the SEB THAAT is generally considerable, as addressed in Table 1 and Fig. 3. And, as already stated, for linear analyses, the reduction in run-time is equal to the reduction in computational effort.

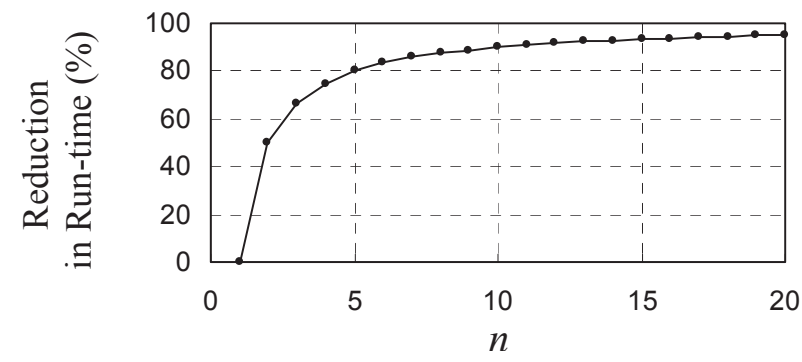

Figure 3: Reduction in the run-time with respect to the enlargement scale $n$, for linear analyses accelerated by the SEB THAAT.

In the other direction, some theoretical studies were carried out. First, enlarging the digitization step, without changing the record at the non-eliminated time stations (see Fig. 4), which is implemented as a simple approach for faster analysis since decades e.g. [58], was studied. It was demonstrated that though in some cases the simple approach leads to good accuracy and reduced computational effort compared to the ordinary analysis, the efficiency is in all cases better, when using the SEB THAAT [59]. Specially, cases were observed, where the result of the simple approach was totally erroneous, while the corresponding result of the SEB THAAT was satisfactory [59].

\begin{tabular}{|l|l|l} 
Original excitation & $\begin{array}{l}\text { Excitation after using } \\
\text { the simple approach }\end{array}$ & $\begin{array}{l}\text { Excitation after using } \\
\text { the SEB THAAT }\end{array}$
\end{tabular}

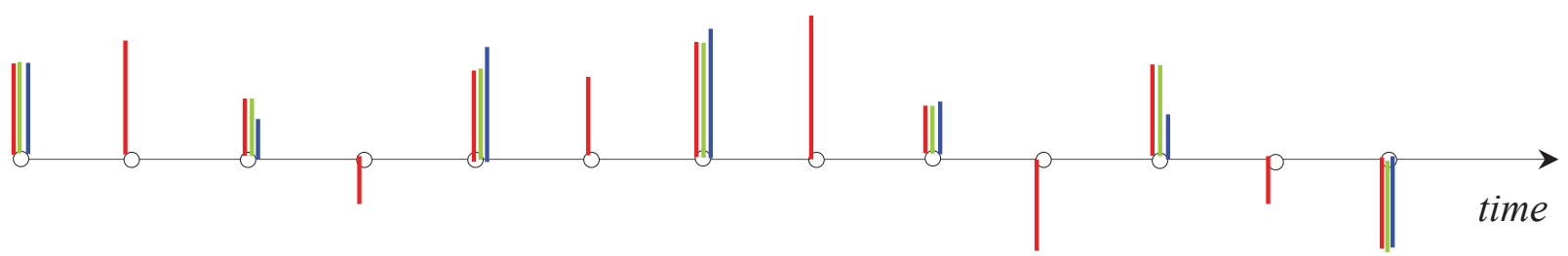

Figure 4: Typical comparison between excitation records in implementation of the SEB THAAT and the traditional simple step enlargement approach considering $n=2$. 
It is then studied whether the inaccuracy because of the SEB THAAT can lead to instability, or in other words, whether the SEB THAAT may negatively affect the responses stability. The response was negative $[1,60]$, i.e. when Eq. (2) is satisfied the responses are numerically stable regardless of implementation of the SEB THAAT. The main reasons are the convergence basis of the SEB THAAT and the relation between convergence and numerical stability in time integration analyses [61-63]. In the next step, selecting values for $a$ and $b$ in Eq. (8.2), different from those stated in Eqs. (11), and subjected to (see [13]):

$$
\sum_{k=1}^{n^{\prime}} b_{k}=\frac{1}{2}
$$

was studied [64]. As the result, though in some examples Eqs. (11) did not present the best alternative, the overall best selection can e considered as stated in Eqs. (11). Another question was on how to consider non-integer values as the enlargement scale $n$. This is essential especially with attention to Fig. 3 and when the $n_{\max }$ available from Eq. (16) satisfies:

$$
1<n_{\max }<2
$$

Two simple approaches to extend the SEB THAAT to:

$$
n, n_{\max }=\frac{p}{q} \quad, \quad p, q \in Z^{+}
$$

and

$$
n, n_{\max } \in R^{+}\left(R^{+}\right. \text {stands for the set of positive real numbers) }
$$

can be found in $[38,39]$.

The effect of nonlinear behavior on the performance of the SEB THAAT was another area for theoretical study. The carried out brief study led to the good performance of the SEB THAAT, when adequate values are assigned to the nonlinearity parameters $[49,65]$. Further study seems essential.

Meanwhile, in response to a question, after a conference presentation, it was demonstrated that the $T$ in Eq. (2) should be related to the response, the accuracy of which, is under study [66]. Some initial study was also carried out on the frequency content of the inaccuracies because of the SEB THAAT [67].

And finally, the most recent study was on the performance of the SEB THAAT when the structural viscous damping is non-classical. The study had a numerical/theoretical nature. As the consequence, for majority of integration methods, the performances of the SEB THAAT in application to classically and non-classically damped analyses are conceptually similar [27]. For other integration methods, the case may be the same as well, though can not be guaranteed before the analysis [27].

\section{THE EXISTING CHALLENGES}

As implied in the previous sections and specifically in Table 1 and Fig. 3, the reduction in computational effort because of implementation of the SEB THAAT can be considerable. Considering this, the simplicity and versatility of the SEB THAAT, the comparisons made between the SEB THAAT and other analysis acceleration methods [1,68], the importance of computational effort in practical structural analyses, and the fact that structural systems become larger and more complicated every new day, the SEB THAAT can be considered a successful analysis acceleration technique in need of further research for broad practical 
implementation. Accordingly, special attention should be paid to the challenges facing the SEB THAAT. Some of the most important challenges are as follows:

The first challenge relates to the $T$ in Eqs. (2), (14) and (16). The $T$ is not only vague, because of the expression "worthwhile contribution" in its definition (see the definition just after Eq. (2)), but also is not computable prior to the analysis. The consequence is a serious problem in determination of $n_{\max }$ and $n$; see Eq. (16). Practical implementation of the SEB THAAT will hence be significantly affected and indeed becomes complicated, the least; i.e. what is the value to be assigned to step enlargement scale $n$ resulting in the determination of the $\left({ }_{f} \Delta t\right)_{\text {new }}$ and $\mathbf{f}_{\text {new }}(t)$ ? Recently, efforts for overcoming this problem are reported (see [31]). These efforts make use of a convergence-based conventional error-control method [23, $69,70]$ and the practical suggestions stated in seismic standards [25, 71]. According to these efforts, the analysis is carried out via sequential time history analyses, each throughout $\left[\begin{array}{ll}0 & t_{\text {end }}^{\prime}\end{array}\right]$ using a special enlargement scale. The repetitive analyses are continued, till two sequential responses are sufficiently close. The resulting analysis seems powerful and versatile, in the limits of structural dynamics problems, but not restricted to satisfaction of Eq. (14). More study on this effort and analyzing problems in real need of run-time reduction are essential.

The second challenge relates to the true nature of many oscillatory behaviors, which is a combination of inertial (structural dynamics) behavior and wave propagation. As implied in Eqs. (1) and (2) and Table 1, the SEB THAAT is mostly applied to analysis of structural dynamic problems. Study on application of the SEB THAAT in analysis of wave propagation problems is complicated, especially because of the CFL condition [72] (this condition upperbounds the time integration step by a coefficient of the element sizes in spatial discretization by finite elements). Despite, successful numerical efforts presented in this regard [29, 30, 48], further detailed study is essential, both in theory, as well as in application. The relaxation method recently proposed for the CFL condition $[73,74]$ seems a good starting point.

The third challenge returns to the purpose of the SEB THAAT, i.e. reduction of the computational effort in time integration analysis of structural systems against digitized excitations. As implied in Eqs. (2) and (14), the SEB THAAT cannot reduce the analysis computational effort, when the excitation digitization step ${ }_{f} \Delta t$ does not dominate Eq. (2), i.e.

$$
\operatorname{Min}\left(\frac{T}{\chi}, \Delta t_{c r}\right) \leq_{f} \Delta t
$$

Overcoming this restriction is a main challenge facing the SEB THAAT for highly oscillatory and highly nonlinear problems, for which $T$ can be sufficiently small to satisfy Eq. (22). Though the ongoing efforts on the first challenge seem effective in easing this challenge, direct efforts to cancel this restriction would be instructive and reasonable. No such effort is reported yet. Enhancement in the accuracy or order of accuracy of the integration scheme and/or the SEB THAAT seems an appropriate solution.

A fourth challenge is implementation of the SEB THAAT in analysis of structural systems subjected simultaneously to several excitations digitized in completely different step-sizes. Considering that many important structural systems, e.g. offshore or super-tall structures, are in this group, overcoming this challenge is of high practical importance. No special effort is reported yet.

And finally, for practical implementation of the SEB THAAT, besides clear determination of the enlargement scale $(n)$ discussed as the first challenge, it is important to have an idea about the resulting reduction in computational effort. Figure 3 clarifies this ambiguity for lin- 
ear analyses. The case is however different for nonlinear analyses, and even there is yet no theoretical guarantee for the reduction of the run-time and computational effort. Especially the method of nonlinearity iteration and the related parameters can significantly affect the reductions. Though in many nonlinear analyses, the reduction in run-time is less than that reported in Fig. 3, the opposite can be correct, as well; see [42, 43, 75]. Considering that nowadays structural dynamic analyses are generally nonlinear, without overcoming this challenge, implementation of the SEB THAAT would hardly be accepted in practice. Yet, no effort is reported.

\section{A LOOK AT THE FUTURE}

In view of the discussions presented in Sections 1-3, the SEB THAAT can be considered as a successful analysis acceleration technique in need of further research. Nevertheless, especially to manage and access the research resources, it is important to have a perspective of the future of the SEB THAAT and the probable needs to this technique.

With attention to Section 3, the SEB THAAT seems in progress in both numerical experiments' direction, as well as the theoretical aspects' direction. The growing sizes of structural models, and complicatedness of analysis requirements from different points of view, e.g. material and excitation, highlight the significance of analysis acceleration. In addition, the seismic recording instrumentation is in progress towards smaller digitization step ${ }_{f} \Delta t$ [76]. Besides, because of the everyday advancement in structural design optimization and the growing popularity of the optimization, the $T$ in Eq. (2) will likely become larger in future. These lead to more chance for ${ }_{f} \Delta t$ to be the governing term in Eq. (2). The consequence is more need to the SEB THAAT, in near- and mid-future. Accordingly, it is reasonable to anticipate efforts to overcome the first challenge addressed in Section 3, i.e. clear determination of the enlargement scale $n$, in near future. The study reported in [31] implies an initial step that should be established, after which extending the SEB THAAT to wave propagation problems can be anticipated for future studies. The next step can be plugging the SEB THAAT in a commercial soft ware, e.g. seismo-struct [77]. With an analysis soft ware equipped with the SEB THAAT, many different numerical tests, considering different structural materials, such as wood, aluminum, epoxy glass composites, different nonlinear behaviors, interaction with completely different behaviors, subjected to different earthquake records, temperature changes, soil-structure-interaction, etc. can be simply carried out. Specifically, efforts on the fourth challenge addressed in Section 3 can be carried out much simpler. In mid- and farfuture, it will be reasonable to try for improving the SEB THAAT, especially to overcome the third challenge addressed in Section 3. This seems possible, either directly with attention to the very details of the technique [1], the integration methods, or even by combining the SEB THAAT with other techniques, such as those proposed in [5-7, 14].

Furthermore, and in view of the mathematical basis of the SEB THAAT $[1,13]$, this technique can be tested in non-seismic problems, where the excitation is not originated in earthquakes. First steps in this area are already taken; see $[32,78]$. Even more, the digitization might be limited to some part or some components of the $\mathbf{f}(t)$ in Eq. (1), or more, to terms of Eq. (1) other than the excitation. Some related studies are already reported [33, 34]. In far future, the SEB THAAT seems having the potential to be accepted as a general tool for data simplification for arbitrary numerical computation. The most important pre-requisite is however to overcome the first challenge addressed in Section 3.

Meanwhile, no anticipation is possible for the future of the fifth challenge, addressed in Section 3. The reason is the same ambiguity for ordinary time history analysis, persisting since decades. A unique solution can however be anticipated for both ambiguities. 


\section{CONCLUDING REMARKS}

As a technique for accelerating time history analysis, by enlarging the excitation records' digitization steps $\left({ }_{f} \Delta t\right)$,

1. The SEB THAAT can be considered a successful analysis acceleration technique, in need of further research.

2. For practical implementation in real problems, there are still challenges to be overcome; the most important challenges can be summarized as:

(a) clear determination of the enlargement scale $(n)$,

(b) providing the capability to successfully implement the SEB THAAT in analysis of wave propagation problems,

(c) providing the capability to successfully implement the SEB THAAT in analysis of highly oscillatory/nonlinear problems,

(d) providing the capability to successfully implement the SEB THAAT in analysis of problems with several excitations completely different in digitization step and time length,

(e) clarifying the amount of run-time and computational effort reduction in nonlinear analyses prior to the analyses.

3. The future of the SEB THAAT is promising, especially considering the improvements in the recording instrumentation.

4. Besides, the challenges addressed in the Point 2 above, some areas for further research are:

(a) Combination of the SEB THAAT, with other analysis acceleration techniques.

(b) Plugging the SEB THAAT in commercial structural analysis soft ware, and application of the SEB THAAT to different time history analyses.

(c) Applying the SEB THAAT to computations other than those in structural and earthquake engineering.

(d) Study on the details of the SEB THAAT, to improve the results accuracies.

Finally, the author anticipates that the SEB THAAT will eventually be extended to a data simplification technique.

\section{REFERENCES}

[1] A. Soroushian, Integration step size and its adequate selection in analysis of structural systems against earthquakes. M. Papadrakakis, V. Plevris, N.D. Lagaros, eds. Computational Methods in Earthquake Engineering Vol 3, Springer, USA, pp. 285-329, 2017.

[2] D. Vamvatsikos, C.A. Cornell, Incremental dynamic analysis. Earthquake Engineering \& Structural Dynamics, 31, 491-514, 2002.

[3] N. Teunisse, L. Demasi, P. Tiso, R. Cavallaro, Reduced basis methods for structurally nonlinear Joined Wings. Aerospace Science and Technology, 68, 486-495, 2017.

[4] Y. Lee, B. Seo, E.T. Lee, Application of model reduction techniques to jacket structures. International Journal of Steel Structures, 15, 1-6, 2015.

[5] J. Kiani, C. Camp, S. Pezeshk, N. Khoshnevis, Application of pool-based active learning in reducing the number of required response history analyses. Computers \& Structures, 241, Article 106355, 2020. 
[6] M. Mousavi, M. Ghafory-Ashtiany, A. Azarbakht, A new indicator of elastic spectral shape for the reliable selection of ground motion records. Earthquake Engineering \& Structural Dynamics, 40, 1403-1416, 2011.

[7] S.A. Moghaddam, M. Ghafory-Ashtiany, Evaluation of a recently proposed ground motion selection method in case of vertically irregular frames. Journal of Seismology and Earthquake Engineering, 17, 165-180, 2015.

[8] D.N. Herting, A general purpose, multi-stage, component modal synthesis method. Finite Elements in Analysis and Design, 1, 153-164, 1985.

[9] D. Rixen, A Lanczos procedure for efficient mode superposition in dynamic analysis. 43rd AIAA/ASME/ASCE/AHS/ASC Structures, Structural Dynamics, and Materials Conference, Denver, Colorado, USA, April 22-25, 2002.

[10] W.L. Wood, Practical time stepping schemes. Oxford, 1990.

[11] T. Belytschko, T.J.R. Hughes, Computational methods for transient analysis. Elsevier, 1983.

[12] W. Kim, J.N. Reddy, A new family of higher-order time integration algorithms for the analysis of structural dynamics. Journal of Applied Mechanics, 84, 071008, 2017.

[13] A. Soroushian, A technique for time integration with steps larger than the excitation steps. Communication in Numerical Methods in Engineering, 24, 2087-2111, 2008.

[14] J.C. Reyes, E. Kalkan, A. Sierra, Fast nonlinear response history analysis. $16^{\text {th }}$ World Conference on Earthquake Engineering (16WCEE), Santiago, Chile, January 9-13, 2017.

[15] M. Hosseini, I. Mirzaei, Simplification of earthquake accelerograms for rapid time history analysis based on the impulsive load concept. M. Papadrakakis, V. Papadopoulos, V. Plevris eds. $4^{\text {th }}$ ECCOMAS Thematic Conference on Computational Methods in Structural Dynamics and Earthquake Engineering (COMPDYN 2013), Kos Island, Greece, June 12-14, 2013.

[16] J. Henrych, Finite models and methods of dynamics in structures. Elsevier, 1990.

[17] K.J. Bathe, Finite element procedures. Prentice-Hall, 2006.

[18] H. Kardestuncer, Finite element handbook. McGraw Hill, 1987.

[19] T. Belytschko, W.K. Liu, B. Moran, Non-linear finite elements for continua and structures. John Wiley \& Sons, 2000.

[20] A. Soroushian, New methods to maintain responses' convergence and control responses' errors in analysis of nonlinear dynamic models of structural systems. Ph.D. Thesis, University of Tehran, Iran, 2003. (in Persian)

[21] P. Wriggers, Computational contact mechanics. John Wiley \& Sons, 2002.

[22] T.J.R. Hughes, K.S. Pister, R.L. Taylor, Implicit-explicit finite elements in nonlinear transient analysis. Computer Methods in Applied Mechanics and Engineering, 17, 159$182,1979$.

[23] R.W. Clough, J. Penzien, Dynamics of structures. McGraw-Hill, 1993.

[24] J.F. McNamara, Solution schemes for problems of nonlinear structural dynamics. ASME Journal of Pressure Vessel Technology, 96, 147-155, 1974. 
[25] NZS 1170. Structural Design Actions, Part 5: Earthquake Actions-New Zealand. New Zealand, 2004.

[26] C.C. Chen, A.R. Robinson, Improved time history analysis for structural dynamics: I. Treatment of rapid variation of excitation and material nonlinearity. ASCE Journal of Structural Engineering, 12, 2496-2513, 1993.

[27] A. Soroushian, On performance of a time integration acceleration technique applied to seismic analysis of non-classically damped structural dynamics. Iranian Journal of Science and Technology, Transactions of Civil Engineering (just accepted).

[28] A. Soroushian, Direct time integration with steps larger than the steps by which the excitations are digitized, Technical Report No. 7510. International Institute of Earthquake Engineering and Seismology (IIEES), Iran, 2011. (In Persian)

[29] M. Erfaninia, A. Soroushian. On reduction of computational cost in analysis of soilstructural-interaction. M. Papadrakakis, M. Fragiadakis eds. $6^{\text {th }}$ ECCOMAS Thematic Conference on Computational Methods in Structural Dynamics and Earthquake Engineering (COMPDYN 2017), Rhodes Island, Greece, June 15-17, 2017.

[30] M-A. Daziano, Evaluation of seismic vulnerability of dams constructed of loose material. Ph.D. Thesis, National University of Tucuman, Argentina, 2017. (in Spanish)

[31] A. Soroushian, Direct time integration from earthquake induced equations of motion with steps larger than conventional and least dependence to the frequency content of the response, Technical Report No. 7537. International Institute of Earthquake Engineering and Seismology (IIEES), Iran, 2018. (In Persian)

[32] A. Soroushian, E.M. Farahani, Efficient static analysis of assemblies of beam-columns subjected to continuous loadings available as digitized records. Frontiers in Built Environment, 4, 215-229, 2019.

[33] A. Soroushian, S. Amiri, Reduction in space for dynamic finite element analysis of assemblies of beam-columns when the mass is available in digitized format. Journal of Applied and Computational Mechanics, DOI: 10.22055/JACM.2019.31603.1898. (in press)

[34] A. Soroushian, S. Amiri, Simultaneous reduction in time and space for dynamic finite element models of beam-column assemblies. Iranian Journal of Science and Technology, Transactions of Civil Engineering, 45, 1265-1279, 2021.

[35] S.N. Penry, W.L. Wood, Comparison of some single-step methods for the numerical solution of the structural dynamic equation. International Journal for Numerical Methods in Engineering, 21, 1941-1955, 1985

[36] T.M. Apostol, Calculus, Vol. I. John Wiley \& Sons,1967.

[37] S. Azad, A.A. Hadad, S., Amiri, A. Soroushian, Case studies on the performance of a transient analysis computational cost reduction technique when applied to analyses with integration methods of order one two and four. D.T. Tsahalis ed. $6^{\text {th }}$ International Conference from "Scientific Computing to Computational Engineering" (6th IC-SCCE), Athens, Greece, July 9-12, 2014.

[38] A. Sabzei., A. Y. Reziakolaei, A. Soroushian, On more versatility for an integration step size enlargement technique in time integration analysis. M. Papadrakakis, V. Papadopoulos, V. Plevris eds. $4^{\text {th }}$ ECCOMAS Thematic Conference on Computational Methods 
in Structural Dynamics and Earthquake Engineering (COMPDYN 2013), Kos Island, Greece, June 12-14, 2013.

[39] A. Soroushian, Y. Zarabimanesh, K. Soleymani, S.M. Khalkhali, A new technique for fractional enlargement of integration steps in transient analysis against digitized excitations. S. Braun, N. Maia, M. de Matos Neves eds. International Conference on Structural Engineering Dynamics (ICEDyn 2017), Ericeira, Portugal, July 3-5, 2017.

[40] X. Zhou, K.K. Tamma, A new unified theory underlying time dependent linear firstorder systems: a prelude to algorithms by design. International Journal for Numerical Methods in Engineering, 60, 1699-740, 2004

[41] D.M. Monro, Fortran 77. Edward Arnold, 1987.

[42] Y. Zarabimanesh, On the possibility to reduce the computational cost of time history analysis of the Milad telecommunication tower. Ms.c. Thesis, International Institute of Earthquake Engineering and Seismology (IIEES), Iran, 2017. (in Persian)

[43] A.A. Hadad, Reducing computational costs in time integration analyses of buildings with irregularities in height because of mass. Ms.c. Thesis, International Institute of Earthquake Engineering and Seismology (IIEES), Iran, 2015. (in Persian)

[44] S. Azad, A study on accelerating time history analysis of bridges. Ms.c. Thesis, International Institute of Earthquake Engineering and Seismology (IIEES), Iran, 2015. (in Persian)

[45] A. Baiani, On the possibility to accelerate time history analysis of buildings with irregularities in plan because of mass distribution. M.Sc. Thesis, University of Pooyandegan Danesh, Iran, 2018. (in press, in Persian)

[46] H. Ghondaghsaz, A Study on a recent technique for more efficient seismic analysis applied to concrete and steel buildings. M.Sc. Thesis, Islamic Azad University West Tehran Branch, Tehran, 2018. (in Persian)

[47] A. Soroushian, A. Jahani Mehrnoosh, Y. Zarabimanesh., M.H. Ghondaghsaz., A. Baiani, A. Zakizadeh, On the performance of a computational cost reduction technique when applied to cooling towers transient analysis. M. Papadrakakis, V. Papadopoulos, G. Stefanou, V. Plevris eds. $7^{\text {th }}$ European Congress on Computational Methods in Applied Sciences and Engineering (ECCOMAS VII), Crete Island, Greece, June 5-10, 2016.

[48] M-A. Daziano, A. Soroushian, On faster transient analysis of structural systems against earthquakes: case study of an earth dam. $8^{\text {th }}$ International Conference on Seismology and Earthquake Engineering (SEE8), Tehran, Iran, November 11-13, 2019.

[49] A. Garakaninezhad, A. Yahyapour, A.A. Hadad, A. Soroushian, A comparison between linear and nonlinear time history analyses after implementing a recent computational cost reduction technique. E. Onate, X. Oliver, A. Huerta eds. $11^{\text {th }}$ World Congress on Computational Mechanics (WCCM2014), Barcelona, Spain, July 25-29, 2014.

[50] A. Garakaninezhad, R.K. Moghadas, On the Performance of a Technique to Accelerate Time Integration when Applied to Space Structures Analyses. M. Papadrakakis, V. Papadopoulos, V. Plevris eds. $4^{\text {th }}$ ECCOMAS Thematic Conference on Computational Methods in Structural Dynamics and Earthquake Engineering (COMPDYN 2013), Kos Island, Greece, June 12-14, 2013. 
[51] O. Bahar, S. Ramezani, Faster time integration analysis for building structures subjected to 3-component earthquakes. M. Papadrakakis, M. Fragiadakis, V. Plevris eds. $3^{r d}$ ECCOMAS Thematic Conference on Computational Methods in Structural Dynamics and Earthquake Engineering (COMPDYN 2011), Corfu, Greece, May 25-28, 2011.

[52] F. Nateghi, M. Yakhchalian, On less computational costs for analysis of silos seismic behaviors by time integration. M. Papadrakakis, M. Fragiadakis, V. Plevris eds. $3^{r d}$ ECCOMAS Thematic Conference on Computational Methods in Structural Dynamics and Earthquake Engineering (COMPDYN 2011), Corfu, Greece, May 25-28, 2011.

[53] F. Nateghi, M. Yakhchalian, An investigation into the effectiveness of a technique proposed for reducing computational cost of time integration in the analysis of silos seismic behaviors. $11^{\text {th }}$ US national congress on computational mechanics (USNCCM 2011), Minneapolis, USA, July 25-28, 2011.

[54] A. Soroushian, A. Saaed, M. Arghavani, M. Rajabi, M.M. Sharifpour, Less computational costs in the analysis of reservoirs seismic behaviours by time integration. J. Náprstek, J. Horáček, M. Okrouhlík, B. Marvalová, F. Verhulst, J.T. Sawicki eds. $10^{\text {th }}$ biennial conference on vibration problems (ICoVP-2011), Prague, Czech Republic, September 5-8, 2011.

[55] M. Bastami, A technique for more efficient time integration applied to seismic analysis of power substation equipment. E. Onate, X. Oliver, A. Huerta eds. $11^{\text {th }}$ World Congress on Computational Mechanics (WCCM2014), Barcelona, Spain, July 25-29, 2014.

[56] A.Y. Reziakolaei, A. Sabzei, A. Soroushian, On the performance of a structural analysis cost reduction technique when applied to residential buildings. M. Papadrakakis, V. Papadopoulos, V. Plevris eds. $4^{\text {th }}$ ECCOMAS Thematic Conference on Computational Methods in Structural Dynamics and Earthquake Engineering (COMPDYN 2013), Kos Island, Greece, June 12-14, 2013.

[57] B. Noble, J.W. Daniel, Applied linear algebra. Prentice Hall, 1977.

[58] O. Azizpour, Evaluating the seismic vulnerability of and proposing multi-variable fragility curves for on pipe-way piping in petrochemical plants. Ph.D. Thesis, International Institute of Earthquake Engineering and Seismology (IIEES), Iran, 2011. (in Persian)

[59] A. Soroushian, P. Farshadmanesh, S. Azad. On the essentiality of techniques to enlarge integration steps in transient analysis against digitized excitations. Journal of Seismology and Earthquake Engineering, 17, 43-60, 2015.

[60] A. Soroushian, A. Garakaninezhad, A. Yahyapour, A.A. Hadad, Performance of a computational cost reduction technique in lengthy time interval analyses. E. Onate, X. Oliver, A. Huerta eds. $11^{\text {th }}$ World Congress on Computational Mechanics (WCCM2014), Barcelona, Spain, July 25-29, 2014.

[61] P. Henrici, Discrete variable methods in ordinary differential equations. Prentice-Hall, 1962.

[62] J.C. Strikwerda, Finite difference schemes and partial differential equations. Wadsworth \& Books/Cole, Pacific Grove, 1989.

[63] R.D. Richtmyer, K.W. Morton, Difference methods for initial value problems. John Wiley \& Sons, 1967. 
[64] A. Zakizadeh, Investigation on the role of the parameter representing the influence of the eliminated excitation stations in the performance of a transient analysis computational cost reduction technique. M.Sc. Thesis, International Institute of Earthquake Engineering and Seismology (IIEES), Iran, 2017. (in Persian)

[65] A. Soroushian, On the performance of a recent technique for more efficient time integration in severe seismic conditions. C-K. Choi ed. $I^{\text {st }}$ International Conference on Advances in Structural Engineering and Mechanics (ASEM'11), Seoul, South Korea, September 18-23, 2011.

[66] A. Soroushian, On the accuracy of accelerations in general implementation of a recently proposed seismic analysis computational cost reduction technique. D.T. Tsahalis ed. $5^{\text {th }}$ International Conference from "Scientific Computing to Computational Engineering" (5th IC-SCCE), Athens, Greece, July 4-7, 2012.

[67] A. Soroushian, M. Hosseini, S.M.K. Khalkhali, On the frequency content of errors originated in a time integration computational cost reduction technique. M. Papadrakakis, V. Papadopoulos, G. Stefanou, V. Plevris eds. $7^{\text {th }}$ European Congress on Computational Methods in Applied Sciences and Engineering (ECCOMAS VII), Crete Island, Greece, June 5-10, 2016.

[68] A. Saaed, A technique for faster seismic analysis of MDOF structural systems. M.Sc. Thesis, International Institute of Earthquake Engineering and Seismology (IIEES), Iran, 2012. (in Persian)

[69] E. Hairer, G. Wanner, Solving ordinary differential equations II: stiff and differentialalgebraic problems. Springer, 1996.

[70] A. Soroushian, J. Farjoodi, More reliable responses for time integration analyses. Structural Engineering and Mechanics, An International Journal, 16, 219-240, 2003.

[71] NZS 1170.5 Supp 1. Structural Design Actions - Part 5: Earthquake Actions. Standards New-Zealand, New Zealand, 2004.

[72] R. Courant, K. Friedrichs, H. Lewy, Über die partiellen differenzengleichungen der mathematischen physik. Mathematische Annalen, 100, 32-74, 1928.

[73] D. Peterseim, M. Schedensack, Relaxing the CFL condition for the wave equation on adaptive meshes. Journal of Scientific Computing, 72, 1196-1213, 2017.

[74] R. Maier, D. Peterseim, Explicit computational wave propagation in microheterogeneous media. BIT Numerical Mathematics, 59, 443-462, 2019.

[75] A. Soroushian, S.R. Mirghaderi, Y. Zarabimanesh, A. Jahani Mehrnoosh, A. Zakizadeh, M.H. Ghondaghsaz, On the possibility to accelerate time history analysis of the Milad telecommunication tower, $10^{\text {th }}$ National Conference on Civil Engineering (10NCCE), Tehran, Iran, April 19-21, 2017. (in Persian)

[76] J. Havskov, G. Alguacil, Instrumentation in earthquake seismology (modern approaches in geophysics). Springer, 2004.

[77] S. Antoniu, R. Pinho, Seismostruct - seismic analysis program by seismosoft, technical manual and user manual. University of Pavia, 2003.

[78] E.M. Farahani, A. Ganji, S. Maalek, A. Soroushian, Reduction of computational cost in FEM analysis of beams subjected to digitized static loadings. $10^{\text {th }}$ National Congress on Civil Engineering (10NCCE), Tehran, Iran, April 19-21, 2017. 